\title{
REPRESENTAÇÕES DE PAPEIS DE GÊNERO NA VIOLÊNCIA CONJUGAL EM INQUÉRITOS POLICIAIS'
}

\author{
(Representations of gender roles in marital violence in \\ police investigations)
}

Lúcia Freitas ${ }^{2}$

(Universidade Estadual de Goiás - UEG)

\begin{abstract}
This article analyzes the representation of roles that men and women take in their discourse as protagonists of domestic violence in police investigations. Data were collected on 20 criminal cases of threat and injury, of Maria da Penha Law, in which victims and offenders had conjugal relations. A critical discourse approach was applied to the texts and the results show how social actors give very specific meanings to violence within a relationship pattern that places them on unequal terms, reflecting traditional values still present in society. Finally, the article stresses the urgency of gender studies to inform legal agents about the specificities of such violence, in order to avoid decisions that do not promote justice and often give normative force to the inequalities.
\end{abstract}

key words: violence, marital relations, gender, discourse

\section{RESUMO}

Este artigo analisa a representação dos papeis que homens e mulheres assumem em seu discurso como protagonistas da violência conjugal a partir

1. O presente artigo é resultado parcial da pesquisa coordenada pela autora, intitulada "Violência contra a mulher em uma cidade do interior de Goiás: silêncio e invisibilidade?", financiada pelo Edital MCT/CNPq/SPM-PR/MDA nº. 57/2008 do Conselho Nacional de Desenvolvimento Científico e Tecnológico (CNPq)

2. Lucia Freitas é doutorada em Linguística pela Universidade de Brasília (UnB). Foi bolsista do Programa de Estágio de Doutorado no Exterior (PDEE) pela CAPEs, tendo sido pesquisadora visitante por quatro meses no Center for Advanced Research in English, na Universidade de Birmingham, Inglaterra. Atualmente, é professora titular da Universidade Estadual de Goiás (UEG) e Coord. de Pesquisa da mesma instituição. Lidera o Grupo de Estudos sobre aspectos histórico-sociais do centro-oeste goiano. 
de seus depoimentos em inquéritos policiais. Os dados foram colhidos em 20 processos penais de ameaça e lesão corporal, enquadrados na Lei Maria da Penha, nos quais vítimas e agressores tinham relações de conjugalidade. À luz da Análise de Discurso Crítica (ADC), os resultados mostram como esses atores sociais conferem à violência significados bem específicos, dentro de um padrão relacional que os posiciona em condições desiguais ainda mantidas na sociedade, com prejuízo maiores para as mulheres. Ao final, o texto alerta para a necessidade de os estudos de gênero informarem a razão jurídica sobre as especificidades dessa violência, a fim de que sejam evitadas decisões que não promovem justiça e muitas vezes dão força normativa às desigualdades.

Palavras-chave: violência, conjugalidade, gênero, discurso

\section{Introdução}

A expressão "violência conjugal" vem sendo usada em estudos recentes sobre "violência contra a mulher" para distinguir o tipo de abuso que atinge as mulheres nas suas relações afetivo-conjugais daqueles que ocorrem em outros contextos, como com filhos, parentes e desconhecidos (Lamoglia e Minayo, 2009). Essa mudança ocorre, fundamentalmente, com a introdução do conceito de gênero (Scott, 1986) no campo de investigações, consolidando uma abordagem focada na participação de homens e mulheres nas relações violentas, considerando os papeis que ambos assumem na sua produção e legitimação. Em consideração a esse novo paradigma, o presente artigo pretende contribuir para a área de estudos da relação gênero e violência, a partir do campo da pesquisa linguística e sua interseção com as ciências sociais. Essa proposta se viabiliza pelo viés teórico da Análise de Discurso Crítica (ADC) com suas ferramentas próprias, pelas quais apresento uma análise dos tipos de atividades que são empreendidas no discurso dos protagonistas dessa violência em um gênero textual próprio do sistema judicial, o inquérito policial. Ao mesmo tempo, promovo uma investigação focada no discurso desse sistema, tendo em vista o poder regulador que este exerce sobre as práticas de violência em geral. 
Neste artigo, portanto, apresento um olhar mais detido sobre os aspectos relacionais dos conflitos de gênero, a partir da representação dos papeis de homens e mulheres em cenas de violência conjugal registradas em depoimentos colhidos dentro do sistema judiciário. Vou-me debruçar sobre um problema social revestido de invisibilidade e silenciamento que é registrado em textos jurídicos, guardados nas dependências dos Fóruns, fora do alcance da maioria das pessoas. Nessa medida, minha tarefa também envolve o compromisso de trazer a público uma realidade acessível apenas a alguns operadores do direito, muitas vezes eles próprios, cegos para a questão que é ofuscada em meio a um emaranhado de ações judiciais.

A seguir, caracterizo os dados deste estudo a partir de sua inserção no sistema de gênero (Fuzer e Barros, 2008) que são os processos penais, do qual fazem parte os inquéritos policiais. Na sequência, apresento o viés teórico-analítico da $\mathrm{ADC}$ e as análises e discussões daí decorrentes. Por fim, discuto algumas questões sobre os papeis de gênero na violência conjugal com destaque para como os aspectos punitivos dos crimes contra a mulher são abordados no judiciário.

\section{A geração dos dados e o contexto da pesquisa}

A pesquisa que originou este artigo compreendeu 20 processos penais de ameaça e lesão corporal, enquadrados na Lei Maria da Penha, nos quais vítimas e agressores tinham relações de conjugalidade. Esses processos foram aleatoriamente escolhidos entre um montante de sessenta e dois registros feitos entre os anos de 2007 e 2008, no Cartório do Crime da cidade de Jaraguá, interior de Goiás. Essa cidade é tomada como campo específico da pesquisa em virtude de minha atuação como professora e pesquisadora na Universidade Estadual de Goiás, Unidade de Jaraguá, onde o projeto original foi proposto. Ao mesmo tempo, essa escolha visa a preencher uma lacuna no que se refere às cidades do interior em geral, uma vez que a maioria das pesquisas (Almeida, 2001; Azevedo, 1985; Fausto, 1984; Gregori, 1993; Grossi e Werba, 2001) retrata o universo das capitais ou 
grandes centros. Dentro dessa orientação, dedico-me, especialmente, a desvendar processos de continuidade ou ruptura com valores, visões de mundo que conduzem quase sempre à violência em contextos cuja herança cultural, a exemplo de Jaraguá, guardam marcas da atuação recente de grupos oligárquicos extremamente autoritários.

\section{O Inquérito Policial dentro do sistema de gêneros textuais do processo penal}

Os processos que fornecem os dados deste estudo são definidos por Fuzer e Barros (2008:48) como "uma série ou sequência de atos conjugados que se realizam e se desenvolvem no tempo, destinandose à aplicação da lei penal no caso concreto". Essa noção é captada pelo conceito de sistema de gêneros, denominado por Bazerman (2005) como os diferentes conjuntos de gêneros textuais produzidos e utilizados de modo organizado e padronizado por um determinado grupo de pessoas. No sistema, um texto segue outro texto em uma seqüência regular e em padrões temporais previsíveis, revelando um fluxo comunicativo típico do grupo que o originou. Esse fluxo compreende a produção e circulação de uma gama muito ampla de textos, classificados por Pimenta (2007) em mais de 130 gêneros textuais específicos. Meu interesse, contudo, recai apenas sobre os documentos que compõem o chamado Inquérito Policial (IP), por razões que se evidenciam a seguir.

O IP é um conjunto de diligências e atos investigatórios realizados por operadores da esfera policial para apurar o fato criminoso e sua autoria. É, portanto, o instrumento formal que reúne as "provas" necesárias para que se possa propor ação penal. Segundo Jesus (2009), compreende-se como provas, os elementos que elucidam os atos e os fatos condizentes às ocorrências, transmitindo a elas condição de certeza e lucidez. Elas podem ser subjetivas, aquelas que transmitem informações e cujas fontes serão as pessoas que participaram direta ou indiretamente dos acontecimentos, ou objetivas e materiais, quando têm como base concreta os vestígios que mediam a realização dos 
crimes. Aqui, interessam-nos especialmente as primeiras, que são registradas nos depoimentos colhidos no IP.

A tomada de depoimento judicial é uma ação chave no sistema que se materializa em vários gêneros textuais, como os "boletins de ocorrência", "termos de depoimentos", "assentada”, "depoimento em auto de prisão em flagrante" e outros. O depoimento no IP possui forma e conteúdo determinados por lei. Segundo Nascimento (2009), a função precípua desse gênero é a apuração dos "fatos" e é o próprio Código de Processo Penal (CPP) que prescreve sua forma e conteúdo. A primeira convenção do que seja um depoimento policial/judicial é que ele ocorre como uma "entrevista” que acontece entre a juíza ou juiz, delegada ou delegado de polícia e os depoentes, vítimas, agressores e testemunhas em um Fórum/Delegacia de Polícia, sobre algum crime que tenha acontecido.

Os depoimentos geram textos de estrutura essencialmente narrativa que privilegiam a representação do conflito. Compreender a lógica dos depoimentos é um ponto de partida para a reconstrução das histórias de violência, uma vez que estas são depreendidas da conjunção dos "fatos" neles apurados e, ao mesmo tempo, é com base neles que alguns gêneros processuais são produzidos em outras fases do processo subsequentes ao IP. Há variações nas representações dos eventos e nas estratégias discursivas que, em geral, apagam, minimizam ou realçam certas agências dos envolvidos, de acordo com os interesses argumentativos dos depoentes. É sobre esses e outros aspectos da representação do conflito e os papeis de seus protagonistas que as análises serão empreendidas. A seguir, apresento o viés teórico que embasa o estudo, bem como as ferramentas analíticas que aplico aos textos.

\section{Representação da violência conjugal pelo viés da Análise de Discurso Crítica}

A forte relação entre a linguagem jurídica e poder justifica uma abordagem crítica do discurso legal. Nessa perspectiva, o referencial teórico-metodógico desta pesquisa sustenta-se na Análise de Discurso 
Crítica, doravante ADC (Fairclough, 2003). Essa forma de pesquisa social crítica propõe-se a estudar a linguagem como prática social, considerando o papel crucial do contexto e a relação que há entre linguagem, poder, dominação, discriminação e controle. A noção de "crítica" significa situar os dados no social e focalizá-los como prática linguístico-discursiva, revelando como estas estão imbricadas com as estruturas sociopolíticas mais abrangentes de poder. A ADC ultrapassa os limites da linguística estrutural e apresenta uma proposta de estudo da linguagem, articulando três níveis: o linguístico, o discursivo e o ideológico-cultural. A vertente proposta por Fairclough (2003) envolve esses três níveis, enfocando a gramática na arquitetura do texto, associando-a ao sentido sócio-histórico desse texto e a uma abordagem crítica das práticas sociais em que ele se insere.

Essa pesquisa se volta para os tipos de atividades que são empreendidas no discurso dos protagonistas da violência, ressaltando suas ações e circunstâncias nos relatos colhidos no IP, para um novo mapeamento da representação do conflito, agora, dirigido para seus atores com seus respectivos papeis e identidades. A noção sobre o termo "atores sociais" (Berger e Luckman, 1966), proposta pela sociologia, considera que estes são todos aqueles que participam na formação das estruturas sociais, por meio de sua prática interativa diária, onde agem com uma gama variada de 'outros' para formar a base das instituições sociais e das identidades. A relação dialética entre papeis e identidades é o ponto central das seções analíticas deste artigo, no qual, por meio de uma abordagem textual específica, buscase identificar como são representados os protagonistas das violências denunciadas nos processos aqui investigados.

Nesse ponto, é importante esclarecer o viés teórico adotado para o termo representação, tratado, aqui, como aspecto experiencial da linguagem (Halliday, 1985; Fairclough, 2003). Em linhas gerais, a representação é um processo no qual eventos, ações, sensações, pensamentos, comportamentos e outras atividades humanas se materializam por meio de uma relação simbólica que envolve muitas escolhas gramaticais e complexos oracionais. Conforme propõem Halliday e Matthiessen (2004), as figuras da realidade ocorrem na 
oração, construindo a representação de idéias que expõem: quem faz o que para quem em que circunstâncias. Ainda segundo os autores, essas representações são acionadas por três componentes básicos: o processo (realizado pelo verbo principal da oração); os participantes do processo (realizados pelos substantivos e grupos nominais) e as circunstâncias associadas ao processo (realizadas por frases preposicionadas, grupos adverbiais, e alguns grupos nominais).

Segundo Halliday e Matthiessen (2004), os processos têm um padrão universal nas línguas humanas, compondo basicamente três tipos principais: os materiais, que constroem eventos pelo uso da energia (bater, agarrar, morder, vir...); os mentais, relacionados com o mundo da nossa consciência, dividem-se em cognitivos (pensar, refletir, entender, acreditar), perceptivos (ver, ouvir, cheirar) e afetivos (gostar, odiar); os relacionais, representando categorias de atribuição e identificação (ser, parecer, tornar-se, ficar, ter, possuir, pertencer). Além desse grupo principal, os autores ainda acrescentam subtipos que compartilham características desses primeiros. Seriam os processos verbais, que pertencem ao "dizer" (falar, dizer, conversar, culpar, criticar, pedir, explicar, questionar); os comportamentais, tipicamente humanos, fisiológicos e psicológicos (respirar, tossir, sorrir, rir, chorar, sonhar) assim como, os existenciais, expressos pelos verbos haver e existir.

Os papeis gramaticais dos participantes nos processos variam segundo o próprio processo. Assim, nos materiais os participantes podem ser ator ou meta; os mentais envolvem experienciador e fenômeno; os relacionais, dependendo do tipo de relação, comportam portador, atributo, identificado, identificador, característica e valor; os verbais envolvem dizente e alvo; os existenciais envolvem o existente; enquanto nos comportamentais o participante principal é denominado comportante. A representação dos participantes ainda envolve algumas escolhas, conforme detalhou van Leeuwen (1996) em seu artigo sobre "a representação dos atores sociais”. Das categorias do autor, utilizo a pessoalidade, em que o ator é constituído com características humanas; a impessoalidade, representado de forma não humana; a nomeação, por um nome/pronome; indeterminação, quando os atores são representados como indivíduos ou grupos não-especificados ou 
anônimos; a categorização, quando constituído por um substantivo que o categorize em uma classe ou grupo; ativação e apassivação, o ator é responsável pela ação ou sofre a ação. Com relação à circunstância, Fairclough (2003) sugere a dicotomia espaço e tempo.

Essas são, portanto, as ferramentas básicas que guiarão a análise sobre a representação dos papeis que vítimas e agressores atribuem a si a seus companheiros nas ações violentas que performam em sua conjugalidade. Na seção seguinte, debruço-me sobre alguns gêneros textuais dos Inquéritos Policiais para observar "quem faz o que pra quem e como" nas cenas violentas.

\section{Atores da violência conjugal e seus papeis}

Nesse momento, ao começar as seções analíticas, apresentarei os dados que "ressoam dos autos", para usar uma expressão própria do meio judiciário. Logo de início, o que se depreende dos gêneros que registram depoimentos em uma mesma peça processual, são narrativas distintas sobre o conflito que, em geral, apresentam uma versão do homem e outra da mulher. Ao serem destacadas dos textos as unidades de informação em que as vítimas e agressores declaram suas ações e as de seus parceiros nas cenas de conflito, sobressaem estratégias que visam apagar a agência agressiva de si mesmo e realçá-la no outro. Para exemplificar a questão, transcrevo os relatos retirados de dois "Termos de depoimento", um da vítima e outro do agressor, colhidos no Inquérito Policial de um processo de lesão corporal. A demanda gira em torno da acusação de uma mulher contra o marido, de tê-la espancado, quando a mesma amamentava o filho, após chegar bêbado em casa e ter sido por ela cobrado por não comprar fraldas para a criança.

A vítima

QUE, na data de ontem dia 24 de novembro de 2007, XXXXXX chegou na residência totalmente embriagado e quando a declarante foi conversar com ele, a respeito da sua embriaguez. XXXXXX xingou a declarante de "vagabunda"; QUE, na data de hoje, dia 25 de novembro de 2007, por volta das $12 \mathrm{~h}$, quando a declarante se encontrava na 
residência da mãe de XXXXXX, $\mathrm{Sr}^{\mathrm{a}}$. XXXXX para almoçar e dali saíram em direção a residência, isto por volta das $16 \mathrm{~h}$, e quando foi conversar com XXXXX para comprar fraldas do filho, este começou a maltratar a declarante, dizendo que os familiares da declarante não prestam, que não vão evoluir e outras coisas dessa natureza menosprezando a todos os membros da família, QUE, chegando em casa a declarante continuou a insistir para ele comprar as fraldas, sendo que XXXXXXX disse que não iria, ocasião em que a declarante pegou o aparelho celular, e nesse momento foi agredida fisicamente por ele, o qual desferiu um murro que acertou os lábios da declarante, sendo que nessa hora a declarante estava com o filho nos braços, amamentando, e mesmo assim foi agredida por XXXXX, o qual ainda "apertou" a declarante e a criança no sofá, fazendo ameaças que se o denunciasse ele acabaria com a vida da declarante; QUE, a declarante tentou levantar-se e sair da residência, ocasião em XXXXX agarrou a declarante e mordeu no braço com objetivo de tomar o celular que a declarante segurava; QUE, todas as agressões foram praticadas dentro de casa e não houve testemunhas oculares do fato; QUE, nada mais disse, nem lhe foi perguntado. Lido e achado conforme, vai devidamente assinado pela autoridade, pela depoente,e por mim, Escrivão que o digitei. (Trecho retirado do Termo de Declaração da vítima, processo 2007. 049. 963.70)

\section{O agressor}

QUE, no domingo passado, dia 25 de novembro, após ter ido até a residência de sua avó, na companhia de XXXXXXX, ao estarem retornando para a residência, iniciou uma discussão por causa, de ciúmes; QUE, nessa discussão, XXXXXXX jogou as chaves da residência sobre o corpo do declarante; QUE, ao chegar na residência, XXXXXXX disse que queria conversar, e o declarante disse que não estava a fim, e a partir desse momento XXXXXXX passou a dizer que o declarante não iria ficar mais na casa e que não seria mais humilhada com palavras, dando o prazo de quinze minutos para o declarante tirar seus objetos; QUE, o declarante começou a colocar as roupas, tendo colocado o aparelho celular sobre o televisor, e nesse momento XXXXXXX pegou o celular e disse que não mais veria o objeto; QUE, o declarante insistiu várias vezes com ela para devolver o celular, e esta ameaçou de atirar o celular contra a parede; QUE, nesse momento o declarante pegou o braço de XXXXXXX, pressionou sobre o sofá, com objetivo de que ela soltasse o objeto; QUE nesse momento, enquanto o declarante tentava tomar o celular, XXXXXXX mordeu nas costas do declarante, ficando a marca; QUE, ao ser mordido, o declarante fez um movimento tentando 
escapar da mordida e provavelmente o cotovelo tenha acertado a boca de XXXXXXX ocasionando a lesão; QUE, XXXXXXX correu até a cozinha, pegou uma faca, e o declarante para evitar maiores complicações saiu de casa, quando então XXXXXXX gritava que iria dar parte do declarante; QUE, no momento em que ocorreu os fatos investigados, estavam presentes na residência apenas XXXXXXX, um filho de três anos, o menor de quarenta dias e o declarante; QUE, houve a separação de quarenta dias e o declarante; QUE, houve separação do casal por várias vezes, mas ao ponto de provocar lesões foi somente esta, embora a XXXXXXX tenha " avançado" sobre o declarante várias vezes. Nada mais disse, nem the foi perguntado. Lido e achado conforme,vai devidamente assinado pela autoridade, pelo declarante, e por mim, XXXXX, Escrivão que o digitei. (Trecho retirado do Termo de Declaração do acusado, processo: 2007.49.963.70).

Em ambas as declarações, os depoentes relatam que o conflito teve início com uma conversa (vítima) ou discussão (agressor). O campo experiencial acionado, portanto, é o que Halliday e Matthiessen (2004) chamam de "campo da consciência", ou seja, aquele em que a ação do falante é mais subjetiva e menos concreta em termos de efeito físico. Os processos predominantes no início do relato são verbais e a esposa tem o papel de dizente (que pratica ações meramente orais), aquela que "foi conversar", "pediu para comprar fraldas" e "continuou a insistir”. Na sequência, a ação subitamente progride para o plano material, "pegou o celular", "foi agredida", "tentou levantar-se e sair". As declarações sobre agressão física estão na voz passiva, o que potencializa a própria passividade da vítima. O filho, o terceiro ator, é trazido à cena também sem atuação material, preso à figura da mãe que o amamenta, com a qual forma um elo, que é ameaçado pela agressão do pai violento.

O discurso da esposa destaca seu papel de vítima passiva na cena de agressão em contraste com o papel ativo de seu marido. Observa-se que a vítima, embora mencione o celular em sua fala, suspende sua introdução, indo diretamente à narrativa de agressão do parceiro. Contudo, segundo o relato deste, ela teria segurado o aparelho com o intuito de ameaçar danificá-lo, o que constitui uma tentativa de violência patrimonial. Essa cena não é incluída no relato da vítima, que menciona o telefone, sem 
explicar para que ou o que faria com ele, momento em que começaram as agressões físicas do marido. As únicas ações materiais do relato da esposa marcam o ato que gera a resposta agressiva do marido e a tentativa de se auto-proteger contra o agressor em busca de um fim para a ação sem revide, mas apenas como uma fuga.

Assim como se detectam estratégias que dissimulam ou apagam a agência agressiva da mulher em seus relatos, essas estratégias são igualmente recorrentes no depoimento do agressor. Retomando os relatos deste, vemos novamente uma estruturação discursiva que apaga ou ameniza o grau de agressividade e agência do ator. A seqüência "fez um movimento ao ser mordido tentando escapar" introduz a explicação para a causa da lesão sofrida pela esposa atestada no laudo do exame de corpo de delito. Novamente se percebe a apassivação da sentença como estratégia para os apagamentos e amenizações da ação agressiva. Aqui, o grupo verbal, "ao ser mordido", atribui a ação a um ator externo, no caso a esposa, retirando a agência do marido. Essa sentença é uma justificativa para a ação anterior "fez um movimento", que por sua vez é a 'provável' explicação para o que teria de fato causado a lesão, "provavelmente o cotovelo tenha acertado a boca". O cotovelo assume a posição de ator da ação material "acertar a boca". A representação de atores sociais em referência a partes de seu corpo é uma estratégia que visa a uma objetificação do sujeito (van Leeuwen, 1996). Isso permite ao ator minimizar seus atributos humanos, de forma a deixar de ser o 'homem' o autor da ação (foi o cotovelo!). Nessa estruturação discursiva, a responsabilidade pelas marcas de agressão física no corpo da esposa é atribuída a ela própria, que teria mordido o marido, ato que causou o movimento quase involuntário do cotovelo que a acertou, causando-lhe a lesão.

Os dois relatos, portanto, denunciam formas de dissimulação da agência violenta dos atores, vítima e agressor, nas cenas de agressão que ambos performam. Essa é uma tendência detectada em outros estudos de violência de gênero (Machado e Magalhães, 1999), que observam uma maneira de focalizar o conflito entre parceiros de forma isolada, realçando suas oposições e não o que os une, sem ser considerada a tensão existente entre os dois e sua respectiva 
singularidade. Para captar melhor essa dinâmica de representação, divido nas duas seções seguintes as análises sobre as estratégias de homens e mulheres recuperadas nos Inquéritos Policiais de outros processos. Assim, exponho a posição dualista que destitui a agência agressiva das pessoas envolvidas na violência, que a torna arbitrária e sem nenhum sentido, como se os dois não participassem ativamente da formação de seu destino. Ao mesmo tempo, revelo as diferenças no modo relacional que homens e mulheres praticam e conferem significado à violência de formas bem específicas.

\subsection{Representação masculina: negação de violência e culpabilização da vítima}

Conforme procurei mostrar na seção anterior, as estruturações discursivas nos relatos dos protagonistas da violência conjugal apagam ou dissimulam a ação agressiva do depoente, tanto o homem como a mulher, e realçam a agressividade dos parceiros. Contudo, há algumas especificidades na articulação desse discurso. $\mathrm{Na}$ fala dos agressores, percebe-se uma estruturação que visa a uma transferência de responsabilidade da agressão destes para as vítimas, de modo a fazer crer que as marcas impressas em seus corpos foram causadas por elas próprias em momentos de descontrole. Ao recurso à objetificação, observado anteriormente, soma-se também o artifício da indeterminação que, segundo van Leeuwen (1996), ocorre quando os atores sociais são representados como indivíduos ou grupos nãoespecificados ou "anônimos". Assim, para dissimular e mesmo apagar a agência agressiva em seus relatos, alguns agressores recorrem à indeterminação em frases cujos processos verbais constroem as cenas de violência, como no recorte a seguir:

(...) QUE, o declarante alega que houve um empurrão em XXXXXX, pegou ela pelo pescoço, empurrando para lá e para cá, e que tal fato aconteceu devido XXXXX ter afirmado que iria levar a filha para fora da cidade; QUE, XXXX estava presente e escutou o que XXXXX havia afirmado. QUE, o declarante afirma ter dado empurrões em XXXXXX 
em outra ocasião, mas que ela não sofreu lesões, "briga de casal" (...) (Trecho retirado do Termo de declaração do acusado, processo: 2008.026.821.67).

Ao enunciar uma representação do conflito estruturada pelo processo verbal "alega que", seguido do grupo existencial "houve um empurrão", faz com que a ação de empurrar, que poderia figurar como um processo material, com efeitos concretos no mundo físico, figure como um processo existencial, perdendo materialidade. Sob essa estrutura, não se pode atribuir subjetividade a um ator, pois não se trata de dizer que alguém empurrou alguém. Trata-se meramente de uma constatação existencial, "houve um empurrão". Assim estruturada, a ação material de empurrar, é representada como um fenômeno existencial, fenômeno este quase sobrenatural, uma vez que não se pode depreender um agente nessa cena, mas apenas um "existente" (Ataíde, 2010), que no caso é o próprio empurrão. O artigo definido "um", que é um quantificador, funciona como elemento de gradação, diminuindo o grau de relevância desse existente na ação. Com esses recursos, o depoente não apenas minimiza a violência, mas também se exclui do cenário violento, como se dele não participasse. Muito embora, nas ações subsequentes, ele afirme que pegou a vítima pelo pescoço, empurrando-a para lá e para cá, a ação é legitimada ante a emoção do agressor frente à investida da vítima de levar sua filha para fora da cidade. É um artifício de legitimação agregado a uma tentativa de comoção. Todas essas estruturações discursivas voltamse, em última instância, para uma transferência de responsabilidade da agressão do homem para a mulher, que é uma estratégia comum de apagamento de agência deste, também identificada em outros estudos (Almeida, 2007). O próximo extrato fornece exemplo sobre a questão:

(...) QUE o declarante afirma que não partiria para cima de XXXXXX e que esta saíra correndo quando deparara-se com o declarante; QUE ao sair, XXXXX empurrara o declarante e saíra correndo, tendo tropeçado e caído ao chão; QUE o declarante nega que tenha dado um chute na perna de XXXXXX; Que afirma que XXXXXXXX, machucara-se em razão da queda e por ter passado embaixo de um arame farpado; QUE o declarante afirma que procurara o pai de 
XXXXXX para dar satisfações do ocorrido mas este não saíra para fora de residência; QUE volta a negar que agredira a vitima XXXXXXXX. (Trechos do Termo de depoimento em auto de prisão em flagrante do processo: 2008.003.731.40)

Nesse recorte, o depoimento está estruturado de forma a fazer crer que as marcas de agressão identificadas no corpo da mulher são decorrentes de seu comportamento no mínimo tresloucado, uma vez que esta correu sem nenhum motivo alegado, apenas ao se deparar com a presença inesperada do companheiro. Nessa fuga infundada, a vítima teria caído e se machucado, ao passar por um arame farpado, provocando em si mesma as lesões atestadas. Este é um discurso de culpabilização, com um desvio de responsabilidade do agressor. É uma construção que revela um comportamento oportunista e destrutivo deste, que nem se apercebe das incongruências de sua narrativa. Ainda que a intenção seja construir a imagem da mulher como inconseqüente, débil e responsabilizá-la pela violência que lhe é desferida, o agressor parece não se dar conta de que seu discurso delata a presença de um medo apavorante e desestruturador, que é a causa implícita da fuga descontrolada de sua esposa. Em sua pesquisa, Almeida (2007) comenta algumas táticas dessa transferência que, em geral, apelam para um discurso sexista, no qual a mulher é tida como irresponsável, provocadora, capaz de atos tresloucados e que a desqualificam diante de seus supostos papeis, de boa mãe, boa esposa, boa dona-de-casa, etc. Nos próximos recortes, vemos mais exemplos dessas estratégias:

(...) Que então voltaram a casa de XXXXX tendo deixado-o em casa enquanto o declarante e XXXXXX saíram a fim de conversar, tomando rumo ao trevo norte desta cidade, quando XXXXX passou a dizer que o declarante queria matá-la, tendo inclusive tentado pular do carro em movimento, contando o declarante a segurou ocasião em que XXXXX o mordeu no braço; Que o declarante voltou com XXXXXXXX para a casa de XXXXXXX e lá estando o casal nervoso o declarante veio a falar algumas "besteiras" para XXXXXX, contudo não proferiu ameaças contra a pessoa de XXXXXX; Que informa também não tê-la agredido e sim usado de força para evitar que XXXXX pulasse do carro em movimento. (Trecho retirado do Termo de declaração do acusado, processo: 2007.049.966.55) 
(...) QUE, o declarante nega que tenha feito ameaça de morte a XXXXXX utilizando uma faca; QUE, o declarante nega que tenha agredido fisicamente XXXXXXX; QUE, o declarante nega que tenha xingado XXXXXXX, alegando inclusive que se faziam sete dias que não conversava com ela. (Trecho retirado do Termo de declaração do acusado, processo: 2007.043.465.96).

Observa-se que esses extratos fornecem mais exemplos para o que já foi demonstrado, acrescentando uma estratégia de apagamento de agência agressiva, agora pelo recurso da negação explícita. A negação é uma das evidências mais recorrentes nos depoimentos dos agressores. A estrutura "nega que tenha + verbo no passado do infinitivo" é uma sequência comum nos relatos e deriva da própria tomada de depoimento, em que o operador do direito faz perguntas ao depoente, cuja resposta é transcrita em seguida. Portanto, as sentenças, "nega que tenha feito ameaça de morte", "nega que tenha xingado" etc., decorrem de perguntas como, "o Sr. ameaçou a Sra. Fulana de tal de morte...", "xingou sua esposa de...". A negativa é, aparentemente, uma estratégia muito direta, e por isso mesmo, cínica, de se eximir de qualquer culpa. Antes de desenvolver mais comentários sobre a negação direta, é preciso ainda mencionar a negação dissimulada pelo esquecimento, outro recurso que se repete nos textos, conforme se vê nos extratos seguintes:

(...) QUE indagado ao interrogando se o mesmo recorda-se de ter empurrado e agredido a vítima, no sábado, quando fora até a residência de sua amásia, tendo esta caído ao chão e batido com a barriga na cama, o interrogando (...) afirma que não recorda-se [sic.]de ter feito tal agressão contra a vítima, [...] QUE o interrogando nega que tenha xingado XXXXX e XXXXXXX de "vagabunda, prostitua, puta"; (Trecho retirado do Termo de declaração do acusado, processo: 200705153210).

QUE, o conduzido afirma a esta autoridade que não se recorda de nada que tenha feito na data de ontem, sendo que só lembra do momento em que estava na sua residência, tomando cerveja; QUE, o conduzido afirma não se recordar de ter xingado, agredido ou ameaçado; QUE, conduzido também não se recorda de ter xingado ou tentado agredir o seu pai; QUE, o conduzido não se recorda de ter resistindo à 
prisão, de ter pego uma garrafa de cerveja para agredir os policiais Militares; QUE, o conduzido alega que havia ingerido muita bebidas alcoólica e por esse motivo não se recorda de nada. (Trecho retirado do Termo de declaração do acusado, processo: 2008.004.523.26).

Aqui, repetem-se os grupos verbais "não se recorda de" + verbo no passado do infinitivo, muito semelhantes às estruturas de negação dos recortes anteriores. A diferença é que essa é uma forma de negação dissimulada pelo esquecimento. O campo acionado é o da consciência, pelo processo mental esquecer. Toda a materialidade se perde ao ser passada ao plano da consciência, e essa perda se reforça na alegação de esquecimento, uma vez que o agressor afirma reiteradas vezes que não se lembra de nada. A agressão, portanto, desaparece, pois não figura nem no plano material nem no mental.

Em seus estudos sobre homens agressores, Guareschi. et. al. (2004) mostram que o homem que exerce violência conjugal não se sente responsável pelos seus atos violentos. Em geral, a violência não é assumida como um problema pessoal, mas da mulher, da família, dos filhos ou problemas econômicos e sociais, justificando, assim seus atos. Essa constatação explica parcialmente as negativas dos homens sobre seus atos violentos. Segundo os autores, eles têm uma percepção rígida e estruturada da realidade, com enorme dificuldade de observar a si mesmos, suas sensações e sentimentos. Confundem o medo com a raiva e a insegurança com uma chamada de atenção sobre comportamentos indesejados.

\section{Representação feminina: as armas "fracas"}

Uma vez detalhadas as estratégias mais comuns de representação no relato dos homens, passo, nesse momento, às análises dessas mesmas estratégias no discurso das mulheres. A literatura especializada sobre as relações de gênero alerta para o risco de se resvalar para uma perspectiva vitimista, na qual, especialmente essas últimas são tratadas sob concepções de passividade e imobilismo. Embora as mulheres sejam significativamente a parte mais afetada pelo conflito conjugal, sendo as vítimas nos processos 
que movem contra os companheiros, em vários pontos dos depoimentos é possível depreender uma violência por elas perpetrada, embora esta seja representada de forma difusa ou mesmo apagada. Autoras como Santos e Izumino (2005) propõem que a situação de violência conjugal encerra uma relação de poder muito complexa e dinâmica, em que as mulheres tem autonomia e poder para mudar a situação na qual porventura se encontrem, conforme demonstram novos estudos sobre o tema (Izumino, 2004). Nesse sentido, analiso o discurso das vítimas, bem como o de seus agressores sobre elas, buscando as conexões entre o fenômeno da violência e os processos de construção social de gênero, começando pelo recorte a seguir:

QUE, na ocasião dos fatos, ao ver que a esposa se achava alcoolizada, tentou impedir que a mesma ingerisse mais bebida (pinga), ocasião em que a mesma ficou nervosa e agarrou no colarinho da camiseta do declarante e em seguida afirmou "me bate, você não é homem não"; QUE ao ser segurado por XXXXXXXXX, o declarante acabou caindo sobre ela, sendo que neste momento, acabou lesionando a boca de XXXXXXXXX, a qual usa aparelho; QUE após se levantarem, o declarante disse para XXXXXX que iria embora, porém, a mesma impediu segurando na camiseta do declarante e proferindo afirmações dizendo "você não é homem não, me bate agora". (Trechos retirados do Termo de Declaração do acusado, processo: 2008.032.974.70)

Este trecho narrativo representa o relato do agressor sobre a vítima. No depoimento desta não há menção alguma à cena. Duas hipóteses explicativas podem ser levantadas: a esposa a teria omitido em suas declarações ou o marido a teria idealizado. Nesse último caso, é possível que, conforme observam Guareschi. et. al. (2004), tal afirmação seja fruto da percepção difusa que tem a maioria dos agressores sobre suas mulheres, por eles vistas como pessoas essencialmente provocativas. Para os autores, esses homens parecem ter uma espécie de lente de aumento para observar cada pequeno detalhe das condutas de suas companheiras e percebem exageradamente os estímulos provocadores de sua violência. Por outro lado, a declaração "você não é homem”, proferida ou não pela mulher, merece uma análise específica. 
Em trabalho anterior sobre o mesmo tema (Freitas e Pinheiro, 2010), observamos que há nos depoimentos dos Inquéritos Policiais em casos de violência de casais uma prevalência de processos materiais e verbais e uma proporcional escassez de processos relacionais. Aqui, a sequência relacional "você não é homem", é usada dentro da ação verbal proferida pela vítima, segundo o agressor, como uma afronta. Para Bourdieu (1999) essa estratégia agressiva associa-se às próprias formas de poder que tentam exercer as mulheres ao se oporem à violência física ou simbólica perpetrada pelos homens. Porém, essas táticas, em geral, são reconhecidas pelo autor como "armas fracas" (Bourdieu, 1999:44), próprias daqueles cujo poder é limitado e que acabam confirmando ainda mais as representações socialmente instituídas. Por outro lado, se podemos detectar uma espécie de violência feminina "fraca", em certos casos, essa violência também se expressa de forma mais contundente, como nos recortes seguintes:

QUE, logo depois, XXXX saiu do bar, e o declarante foi atrás, sendo que na Rua acima, alcançou XXXX e disse: "XXXX você não devia ter falado aquilo para mim (você não é homem); QUE, nesse momento, XXXX repetiu tais palavras; QUE, nesse momento, o declarante deu dois empurrões em XXXX, e esta pegou um pedaço de madeira, e o declarante vendo a sua intenção, jogou a bicicleta de sua propriedade contra XXXX; (Trechos retirado do Termo de depoimento do agressor no processo: 2007.043.487.42)

QUE, na data de ontem, dia 15 de setembro de 2007, por volta das $18 \mathrm{~h}$ a declarante se encontrava no Bar do XXXX, na Vila Colombo, e naquele local, XXXX também se fazia presente e começou a xingar a declarante de "vagabunda", "puta", "piranha", que não passava de uma prostituta", que era mulher da pior espécie" e outras palavras ofensivas [...] em dado momento, a declarante conseguiu segurar a bicicleta, desequilibrando XXXX, e a declarante então pegou uma táboa com a qual utilizou para sua defesa, e XXXX, pegando novamente a bicicleta, a atirou a declarante, fazendo com que a taboa fosse solta. (Trechos retirado do Termo de depoimento da vítima no processo: 2007.043.487.42)

Observa-se, nesses relatos, uma progressão da violência do nível verbal, dos xingamentos, ao material, da violência física 
instrumentalizada, aquela em que se utilizam instrumentos ou objetos como armas para agredir alguém. Com relação aos primeiros, novamente vemos a declaração "você não é homem”, atribuída à fala da mulher para agredir o marido, em oposição à série de palavrões que ele teria proferido contra ela, segundo o relato da mesma. Em sua análise sobre xingamentos, Zanello (2008) chama atenção para os aspectos morais que eles assumem nas oposições dirigidas a homens e mulheres. Quando dirigidos às últimas, os palavrões tem sempre caráter sexual ativo, tais como "puta”, "prostituta", "piranha”, "safada" e assim por diante. Já para os homens, é considerada extremamente ofensiva qualquer referência contra sua virilidade.

Tais considerações explicam porque a simples negação da masculinidade, como na fatídica declaração "você não é homem”, é suficiente para configurar uma ofensa. E, quanto maior o grau de negação do caráter viril, mais inadmissível é o xingamento. Tão inadmissível que não há na pesquisa nenhum registro de palavrão proferido pelas mulheres contra os maridos. E as que se arvoraram a pôr em xeque a masculinidade de seus companheiros, tiveram de arcar com as graves consequências de seu ato, entre elas as próprios ações de auto-defesa em que elas se armam contra a fúria dos maridos, conforme os recortes acima e os próximos que tomo, a seguir:

Vítima

QUE, em seguida a essas acusações, XXXXXX passou a dar empurrões na declarante, empurrando rumo a porta, e quando chegou pelo lado de fora, XXXXXX abaixou para pegar uma pedra e nesse hora a declarante pegou um pedaço de madeira e atirou contra XXXXXX; (Trecho retirado do Termo de depoimento da vítima do processo: 2007.043.465.96)

Agressor

QUE, enquanto o declarante mandava XXXXX sair, caminhando na direção dela, a esposa do declarante, $\mathrm{XXXXXX}$, com um pedaço de madeira, desferiu um primeiro golpe que acertou as costas (região lombar), em seguida, desferiu outra paulada que atingiu o ombro e por fim, desferiu a terceira paulada que acertou a cabeça do declarante, ocasionando um ligeiro desmaio; (Trecho retirado do Termo de depoimento do acusado do processo: 2007.043.465.96) 
Observa-se que, em seu relato, a vítima representa a ação de atirar um pedaço de madeira no declarante, de forma direta, com um processo material, e de forma ativa, na qual atribui claramente a si mesma a agência nessa cena. É, portanto uma representação em que a protagonista assume responsabilidade por seu ato. Os possíveis apagamentos só podem ser depreendidos do relato do marido, que traz elementos que não foram narrados pela esposa. É o caso do número de pauladas que lhe ocasionaram o "ligeiro" desmaio, bem como da cena em que a irmã da esposa, arma-se com um tijolo e uma barra de ferro para ameaçar ou se defender do agressor.

Ainda que alguns depoimentos denunciem, velada ou abertamente, a violência empreendida pelas próprias mulheres contra seus companheiros, esta raramente atinge as proporções da violência por eles perpetrada contra elas. Conforme detectou Strey (2004), casos denunciados em que o homem é vítima de sua companheira são bastante reduzidos e, quando acontecem, em geral, estão relacionados a situações de auto-defesa. A maior vulnerabilidade da mulher fica evidente não apenas nos números de processos de agressão, como nos laudos dos exames de corpo de delito que também fazem parte do IP, em que a violência, ali atestada contra as mulheres, denota uma violência simbólica, sempre subjacente à física, cujos danos psicológicos e morais, em geral, podem ser até mais devastadores (Almeida, 2007).

\section{Considerações finais}

Os processos penais que forneceram os dados para análise sobre a violência nas relações de gênero, no contexto desta pesquisa, expressam uma realidade social a partir dos discursos próprios de um sistema que, por sua vez, é o agente público responsável pelo seu combate. Assim, os inquéritos policiais e os processos penais gerados a partir de denúncias de "brigas de casais" são dados oficiais dessa realidade que não chegam a representá-la no todo, mas que a registram, fornecendo informações valiosas sobre um fenômeno que ainda é silenciado. $\mathrm{O}$ viés teórico provido 
pelos estudos de gênero contribuiu para que as pesquisas sobre esse fenômeno o abordassem dentro de uma perspectiva menos dualista, combatendo simplificações do tipo "macho culpado e mulher vítima", que inspira uma construção facilitada do problema. Contudo, ao longo das análises, esse mesmo viés revelou que os valores e prerrogativas culturais que definem os tradicionais papeis de gênero ainda dão sentido a essa violência e a promovem.

Embora fique claro que homens e mulheres tem, inquestionavelmente, um papel ativo na violência conjugal, as análises das representações dos protagonistas desse fenômeno mostram que ambos conferem a ela significados bem específicos, dentro de um padrão relacional que os posiciona em condições desiguais ainda mantidas na sociedade, com prejuízo maiores para as mulheres. Ficam, portanto, muito evidentes nas análises os valores e prerrogativas culturais que definem os tradicionais papeis do gênero masculino e feminino, quais sejam, liberdade, poder, dominação, força, violência e superioridade, em relação ao primeiro, e submissão, passividade, fraqueza e inferioridade, em relação ao último. Todo o rol de agressões levantadas neste estudo são signos de uma linguagem coercitiva usada pelos casais na disputa do poder na relação, mas cujas consequências são a penalização do corpo feminino e seu sofrimento físico e psicológico, em detrimento do exercício ativo e brutal dos desejos de masculinidades hegemônicas.

Essas considerações evidenciam que a premissa de que a violência conjugal é relacional não pode ser usada para justificar a aceitação da Justiça de formas cruéis, que incluem todo o rol de brutalidades da conjugalidade, como uma mera comunicação idiossincrática entre parceiros. Assumida como uma simples idiossincrasia de casais, a violência é banalizada e se perdem de vista tanto a perspectiva teórica de gênero sobre essas relações, quanto os aspectos criminais delas. Esses últimos são particularmente distorcidos, como em casos em que juízes arquivam processos em que as mulheres perdoam brutalidades de seus maridos que incluem até facada no olho, como observamos em um caso, sem imputar ao agressor qualquer penalidade sobre o crime cometido. 
O número crescente de mulheres que recorrem à justiça contra a violência dos parceiros sinaliza para uma proporcional busca destas sobre seus direitos legais. Contudo, as pesquisas mostram que a resposta do judiciário segue os mesmos moldes do caráter conservador e distanciado desse sistema, sem nenhum engajamento às causas humanitárias que cercam o problema. Sob uma pretensa imparcialidade, o judiciário acaba por promover arquivamentos e suspensões, extinguindo a punibilidade dos réus. Proporcionalmente, expõe as mulheres a retratações humilhantes, que as tornam verdadeiras rés nos crimes de que foram vítimas. Nesse quadro, o discurso jurídico alinha-se de várias formas ao domínio tradicional patriarcal, redobrando a força normativa deste, com vínculos bastante imprecisos ao ideal igualitário que, supostamente, deveria garantir.

A Justiça tem de ter um posicionamento claro e consciente sobre as questões de punibilidade nesses casos. Nessa medida, mais uma vez o viés teórico dos estudos de gênero deve informar a razão jurídica sobre as especificidades dessa violência. É preciso que se reconheça sua associação com uma realidade bem mais ampla, da qual as brigas particulares de casais isolados constituem um fenômeno mundial de proporções que precisam ser combatidas, para que se deem andamento aos projetos igualitários e humanísticos das sociedades ditas "modernas".

Recebido em: 06/03/2011

Aprovado em: 10/05/2011

luciadefreitas@hotmail.com

\section{Referências bibliográficas}

Almeida R. O. Mulheres que matam: universo imaginário do crime no feminino. Rio de Janeiro: Relume Dumará, 2001.

Almeida, S. S. Violência de gênero e políticas. Rio de Janeiro: Editora UFRJ, 2007.

Azevedo, M. A. Mulheres espancadas: A violência denunciada, São Paulo, Cortez, 1985. 
Ataíde, C. Uma abordagem sistêmico-funcional da categoria gramatical de sujeito.

Revista Interdisciplinar, Ano 5, v. 12, jul-dez de 2010, p. 227-243. Disponível em: <http://www.posgrap.ufs.br/periodicos/interdisciplinar/revistas/ARQ_ INTER_12/INTER12_17.pdf>. Acesso em: Dez. 2010.

Bazerman, C. Gêneros textuais, tipificação e interação. Tradução e organização de Angela Paiva Dionísio e Judith Chambliss Hoffnagel. São Paulo: Cortez, 2005.

Berger, P. L. ; Luckmann, T. The social construction of reality. Garden City: Doubleday Anchor, 1966.

Bourdieu, P. A dominação masculina. (Tradução Maria Helena Kuhner). Rio de Janeiro: Bertrand Brasil, 1999.

Fairclough, N. Analysing discourse. New York: Routledge, 2003.

Fausto, B. Crime e cotidiano. A criminalidade em São Paulo (1880-1924), São Paulo, Brasiliense, 1984.

Freitas, L. G.; Pinheiro, V. Atores da violência de gênero: suas narrativas no inquérito policial. In: Zyngier, S. ; Viana, V. (Eds.) Avaliações e perspectivas: estudos empíricos em letras. Rio de Janeiro: UFRJ, 2010. p. 223-243.

Fuzer, C. ; Barros, N. C. Processo penal como sistema de gêneros. Linguagem em (Dis)curso - LemD, v. 8, n. 1, jan./abr, 2008. p. 43-64. Disponível em: $<$ http://www3.unisul.br/paginas/ensino/pos/linguagem/0801/080102. pdf $>$ Acesso em: Set. de 2010.

Gregori, M. F. Cenas e queixas: um estudo sobre mulheres, relações violentas e a prática feminista. Rio de Janeiro: Paz e Terra, 1993.

Grossi P. K. ; Werba G. C. (Orgs), Violências e gênero: coisas que a gente não gostaria de saber, Porto Alegre: EDIPUCRS, 2001.

Guareschi, N. et. al. Problematizando as práticas psicológicas no modo de entender a violência. In: Strey, M. N.; Azambuja, M. P. R. ; Jaeger, F. P. (Orgs.). Violência, gênero e políticas públicas. Porto Alegre: EDIPUCRS, 2004 p.117-214.

Halliday, M. A. K. An introduction to functional grammar. London: Edward Arnold, 1985.

Halliday, M. A. K.; Matthiessen, C. An introduction to functional grammar. 3 ed. London: Edward Arnold, 2004 
Izumino, W. P. Justiça e violência contra a mulher. $2^{\mathrm{a}}$ ed. São Paulo: Annablume, 2004.

Jesus, S. N. A subjetividade em boletins de ocorrência. In: ANAIS, IV SEAD Seminário de Estudos em Análise do Discurso 1969-2009: Memória e História na/a Análise do Discurso, Universidade Federal do Rio Grande do Sul. Porto Alegre, de 10 a 13 de Novembro de 2009. Disponível em: <http://www.discurso. ufrgs.br/sead/paineis/Sergio_Nunes.pdf>. Acesso em Dez. 2010.

Lamoglia, C. V. A.; Minayo, M. C. S. Violência conjugal, um problema social e de saúde pública: estudo em uma delegacia do interior do Estado do Rio de Janeiro. Ciência e Saúde Coletiva, Vol. 14, N. 2, abril, 2009, p. 595-604

Machado, L. Z. Magalhães, M. T. B. "Violência conjugal: os espelhos e as marcas. In: Suarez, M. ; Bandeira, L. (Orgs.). Violência, gênero e crime no Distrito Federal. Brasília: Paralelo 15, Editora da UnB, 1999. p.173-138.

Nascimento, A. B. A retextualização como instrumento de manipulação no discurso jurídico penal. Dissertação de mestrado do Programa de PósGraduação em Estudos Linguísticos, da Faculdade de Letras da UFMG, Belo Horizonte, 2007. Disponível em: <http://www.bibliotecadigital.ufmg. $\mathrm{br} /$ dspace/bitstream/1843/VCSA-77SPU2/1/disserta_o_de_mestrado_ gueda_vers_o_final.pdf $>$. Acesso em: Dezembro de 2010.

Pimenta, V. R. Textos forenses: Um estudo de seus gêneros textuais e sua relevância para o gênero "sentença.". Dissertação de mestrado apresentada à Pós Graduação em Linguística do Instituto de Letras da Universidade Federal de Uberlândia, MG, 2007, 501 f.

Rodrigues, M. C. C. Contributos para a análise da linguagem jurídica e da interacção verbal na sala de audiências. 2005. 512 p. Tese (Doutorado em Letras) - Universidade de Coimbra, Coimbra, 2005.

Santos, C. M. ; Izumino, W. P. Violência contra as mulheres e violência de gênero: notas sobre estudos feministas no Brasil. Revista E.I.A.L. Estudios interdisciplinarios de América Latina y El Caribe. Universidade de Tel Aviv, 2005. Disponível em: <http://www.fag.edu.br/professores/gspreussler/ Direitos\%20Humanos/Viol\%EAncia\%20de\%20G\%EAnero.pdf> Acesso em: Set. de 2010.

Scott, J. W. Gender: A useful category of historical analysis". The American Historical Review. Vol 91, n. 5, Dez. 1986, p. 1053-1075. Disponível em: 
http://links.jstor.org/sici?sici=00028762\%28198612\%2991\%3A5\%3C105 3\%3AGAUCOH\%3E2.0.CO\%3B2-Z> Aacesso em: Set. de 2010

Strey, M. N. Violência de gênero: uma questão complexa e interminável. In: Strey, M. N.; Azambuja, M. P. R.; Jeager, F. P. (Orgs). Violência, gênero e políticas públicas. Porto Alegre: Edipucrs, 2004. p.13-43.

Van Leeuwen, T. The representation of social actors. In: Caldas-Coulthard. C. R. ; Coulthard, M. Texts and Practices. Readings in critical discourse analysis. London: Routledge, 1996, p. 33-70.

Zanello, V. Xingamentos: entre a ofensa e a erótica. Anais: ar 8 - Corpo, Violência e Poder. Florianópolis, 2008. Disponível em: $<$ http://www. fazendogenero.ufsc.br/8/sts/ST33/Valeska_Zanello_33.pdf $>$. Acesso em: Dez. de 2010. 